\title{
Relaciones económicas entre la Comunidad Económica Europea y América Latina*
}

\begin{abstract}
A LDO FERRER, ex Ministro de Economia Argentino, ha sido Consultor del CIES. Ha publicado La Economia Argentina: etapas de su desarrollo y problemas actuales (1968). Es coautor de Dependencia político-económica de América Latina.
\end{abstract}

\section{I. - DEBILITAMIENTO DE LA POSICIÓN LATINOAMIERICANA EN LA ECONOMÍA COMUNITARIA}

\section{Tendencias del comercio mundial}

La América Latina ha venido perdiendo peso relativo en las relaciones externas de la CEE. Mientras las exportaciones de la América Latina a la CEE de 6 aumentaron en $115 \%$ entre 1960 y 1970, las importaciones extra-CEE crecieron en $170 \%$. Si se toma en cuenta el comercio extra-CEE, la disminución de la participación latinoamericana en las transacciones de los países comunitarios es aún más notable. Las relaciones comerciales con el Reino Unido han

- Este documento ha sido elaborado a solicitud del INTAL para ser presentado en las reuniones que el Instituto y el BW mantendrán con el Consejo de Delegados del Instituto Italo Latino Americano, en la Ciudad de Ḿ́xico, el próximo mes de diciembre.

En el documento se trata de ubicar la evolución de los vínculos entre la CEE y la América Latina en el marco del comportamiento de la economia mundial en los últimos lustros. Asimismo, se procura evaluar las perspectivas de esos vínculos tomando en cuenta la evolución previsible de las relaciones cconómicas internacionales y las consecuencias de las negociaciones actualmente en curso en el seno del GATT y el FMI. Del mismo modo, se procura identificar los principales cambios en el desarrollo económico de la América Latina y su impacto en las relaciones con la GEE y el conjunto de los paises avanzados. En el informe se trata de ubicar la posición que los vínculos con la América Latina ocupan en las relaciones externas de la CEE y la repercusión en aquellos de la ampliación de la CEE, la política agrícola común y los acuerdos especiales existentes con otros paises en desarrollo.

Por último, en el marco de las tendencias predominantes se identifican las áreas de cooperación que son actualmente objeto, o pueden serlo, de decisiones concretas de la CEE, de los países latinoamericanos y de organismo como el BID, para promover la profundización de los vínculos entre ambos espacios económicos. 
tenido un comportamiento todavía más desfavorable y las exportaciones se mantienen prácticamente estancadas en la última década. De este modo, el grado de apertura de las economías comunitarias hacia la América Latina ha declinado sensiblemente. En 1958 la relación entre las importaciones de origen latinoamericano y el producto bruto de la CEE de 6 era de 1,01. En 1970 la proporción declinó a 0,74. Para el Reino Unido la caída fue más pronunciada: 1,04 y 0,55 .

No se trata de que las exportaciones latinoamericanas a la CEE de 6 hayan tenido un comportamiento particularmente desfavorable. Por el contrario, han crecido un $50 \%$ más que el conjunto de las exportaciones de la región en la última década y aumentaron su participación en las exportaciones totales del $18 \%$ en 1960 al $22 \%$ en 1970. Si se incorporan las exportaciones al Reino Unido, la evolución es menos favorable por el notable deterioro de los vínculos entre la América Latina y ese país. Salvo el comercio intra-latinoamericano y las transacciones con países desarrollados con los cuales el peso relativo de los vínculos comerciales es aún débil (Japón y Canadá) las exportaciones a la CEE son las de más rápido crecimiento en el conjunto del comercio exterior latinoamericano.

Pese a la evolución relativa favorable de las exportáciones de la América Latina a la CEE se advierte el deterioro de la posición de la región en las relaciones comerciales extra-GEE. Esta tendencia refleja el comportamiento general de los vínculos comerciales de la América Latinà con el resto del mundo. Mientras entre 1960 y 1970 el valor de las exportaciones mundiales aumentó en 9,3\% anual, las de América Latina sólo crecieron en $5,6 \%$. De este modo, la participación latinoamericana en el comercio mundial disminuyó del $7 \%$ al $5 \%$ entre esos años.

Las causas del comportamiento de las exportaciones latinoamericanas debe buscarse en la composición de las mismas y en la vinculación de esa composición con la evolución del comercio mundial. Pese al significativo aumento de las exportaciones de manufacturas, los productos primarios continúan constituyendo más del $80 \%$ de las exportaciones latinoamericanas. $Y$ los productos primarios han venido perdiendo peso relativo en el conjunto del comercio mundial. Además sus términos de intercambio han declinado en el largo plazo. Los alimentos y materias primas representaban el 34,1 \% de las exportaciones mundiales en 1960 y el 24,1 \% en 1970 . Incluso los combustibles perdieron posición relativa $(9,9 \%$ a $9,4 \%)$. Además, dentro del comercio mundial de manufacturas, que es el de más rápido crecimiento, la participación latinoamericana se refiere principalmente a rubros que tienen un comportamiento menos dinámico. Las exportaciones mundiales de manufacturas distintas 
de los productos químicos y bienes de capital (provenientes de las industrias básicas), disminuyeron su participación en las exportaciones mundiales de manufacturas del $50 \%$ al $46 \%$ entre 1960 y 1970.

La tasa de crecimiento de las exportaciones mundiales de productos primarios, en los cuales se concentra el grueso de las exportaciones latinoamericanas, es la mitad de la correspondiente a. la de productos químicos y bienes de capital.

El comportamiento reciente de la composición de las exportaciones mundiales de manufacturas reflejan tendencias de largo plazo que incrementan la importancia relativa de las manufacturas provenientes de las industrias dinámicas (químicas y mecánicas). Según Maizels, las exportaciones derivadas de esas industrias en los principales países exportadores, representaron en 1899 el $39 \%$ de las exportaciones totales de manufacturas, en 1920 el $50 \%$ y en 1959 el $71 \%$. La tendencia conserva plena vigencia.

En cambio, el comportamiento de las exportaciones mundiales de productos primarios es un fenómeno típico de la postguerra. Entre 1913 y 1937 cuando se incorporan numerosos países periféricos al comercio internacional, las exportaciones mundiales de productos primarios crecen más rápido que las de manufacturas y aumentan su participación en las exportaciones mundiales del $36 \%$ al $50 \%$. Los países periféricos, incluyendo la América Latina, cumplieron un papel importante en esta expansión y en vísperas de la Segunda Guerra Mundial proporcionaban alrededor del $50 \%$ de las exportaciones mundiales de productos primarios. Esta participación declinó al $40 \%$ hacia 1970.

En conclusión, el comercio de los países y regiones en desarrollo, como la América Latina, concentrado en la exportación de productos primarios, se ha visto atrapado por dos procesos convergentes: el débil crecimiento relativo de esas exportaciones y la mayor capacidad competitiva y peso relativo en las mismas de las provenientes de los mismos paises industrializados. ${ }^{2}$

Estas tendencias del comercio mundial modificaron apreciablemente las relaciones económicas internacionales. Los paises en desarrollo perdieron, como la América Latina, posición relativa en el comercio mundial. Su participación en las exportaciones mundiales declinó del $21 \%$ al $17 \%$ entre 1960 y 1970 . La rápida expansión del comercio mundial se apoyó en las exportaciones prove-

${ }^{2}$ Alfred Maizels, Industrial growth and world trade, Cambridge University Press, Londres, 1963.

${ }^{2}$ La política agrícola común de la CEE ha contribuido a reforzar este segundo proceso. 
nientes de los países industriales de economía de mercado que au. mentaron su participación en las exportaciones mundiales del $67 \%$ al $72 \%$ entre aquellos años. La de los países de planificación central se mantuvo prácticamente sin cambios en torno del $12 \%$.

El comercio mundial de postguerra se apoya en la expansión del comercio de manufactura entre los propios países industriales. Estos constituyeron el principal mercado para sus exportaciones destinándole el $74 \%$ de las mismas en 1970 contra el $66 \%$ en 1960. Este comercio entre países avanzados aumentó su participación en el conjunto mundial del $42 \%$ al $51 \%$ entre esos años. Mientras los países avanzados aumentaron el grado de interdependencia y apertura recíproca como to revela el crecimiento de la relación entre las importaciones provenientes de los países industriales y el producto de cada uno de esos países, lo contrario ocurre con respecto a los países de la periferia. Frente a estos los países industrializados aumentan su nivel de autoabastecimiento. Una excepción notable de estas tendencias es Japón que, en cierto sentido, está jugando en la economía contemporánea el mismo papel que jugó el Reino Unido desde mediados del siglo xrx hasta la Primera Guerra Mundial, aunque sin alcanzar todavía la posición que la economía británica llegó a ocupar en aquellos años en la economía mundial.

\section{Comportamiento de la CEE}

Las tendencias del comercio mundial se reflejan en las transacciones de la GEE. Las importaciones de productos primarios disminuyeron del $72 \%$ al $55 \%$ de las importaciones extra-CEE entre 1958 y 1970. Excluyendo los combustibles la disminución es del $55 \%$ al $38 \%$. Las importaciones de manufacturas aumentaron del $28 \%$ aI $45 \%$ entre aquellos años. Este comportamiento de las importaciones comunitarias de productos primarios influye, a su vez, en el comercio mundial de esos productos visto que la GEE representa aproximadamente un tercio del mismo.

El conjunto de los países en desarrollo, como la América Latina, ha perdido importancia relativa en las transacciones extra-CEE. Entre 1958 y 1970 las importaciones de ese origen disminuyeron del $42 \%$ al $35 \%$ de las importaciones totales de la GEE de 6. Para el Reino Unido entre los mismos años la disminución fue del $68 \%$ al $49 \%$.

La rápida expansión del comercio intra-CEE puede concebirse como un proceso que profundiza las tendencias imperantes en las relaciones entre el conjunto de los países industriales avanzados. Las exportaciones intra-CEE de 6 sobre las exportaciones totales de los 
países miembros pasaron del $30 \%$ al $50 \%$ entre 1958 y 1970 . Se advierte, pues, una drástica caída de las importaciones extra-CEE en el conjunto de las importaciones de los países miembros. La relación entre las importaciones intra-CEE de 6 y el producto total de los países miembros aumentó del $4,2 \%$ al $8,8 \%$ entre aquellos años reflejando la creciente interdependencia entre los 6 países. Pero la reducción del peso relativo de las transacciones extra-CEE no disminuyó el grado de apertura de la GEE hacia otros países desarrollados. La relación entre importaciones de este origen y el producto comunitario creció ligeramente entre 1958 y 1970 pasando del $5,2 \%$ el $5,4 \%$. En el conjunto de las importaciones extra-CEE, las provenientes de otros países desarrollados aumentaron del $53 \%$ al $58 \%$ entre 1958 y 1970 . En consecuencia, el proceso de integración comunitaria sólo repercutió negativamente en la apertura hacia el mundo en desarrollo para los cuales el coeficiente importaciones/producto disminuyó del $4,2 \%$ al 3,3\% entre los años señalados. Esto es yálido inclusive para los países asociados a la GEE bajo el Acuerdo de Yaundé. El deterioro de la posición relativa de los países en desarrollo en el mercado comunitario obedeció al comportamiento de las importaciones de productos primarios. Además, influyó el hecho de que el proceso de integración comunitario fuera particularmente intenso en el intercambio de productos primarios, desplazando a los países en desarrollo.

\section{Incidencia de la politica agricola comuin y el Acuerdo de Yaundé}

Se advierte que el comportamiento de las exportaciones de la América Latina a la CEE responde a tendencias generalizadas en el comercio internacional. Pero, en el caso específico de la GEE, algunos aspectos de las políticas comunitarias han tendido a deteriorar aún más la posición latinoamericana. En lo que se refiere a las importaciones comunitarias de productos agxícolas de clima templado, de interés particular para los países del Cono Sur de la América Latina, gravita negativamente la política agrícola común. Esta abarca ya más del $90 \%$ de la producción comunitaria y se refiere a productos directamente competitivos de la producción latinoamericana. El estímulo a la producción y el intercambio en la GEE ha elevado sustancialmente los niveles de autoabastecimiento comunitario que pasó del $83 \%$ a más del $90 \%$ entre 1958 y 1970. La expansión del comercio intra-GEE de productos agrícolas ha sido particularmente intensa. Mientras aumentó en $195 \%$ entre 1963 y 1970, las importaciones de productos agropecuarios desde el resto del mundo crecieron en $44 \%$. La incertidumbre generada por la aplicación de 
derechos móviles sobre diversos productos y la presión de los excedentes comunitarios en rubros como trigo blando, azúcar, mantequilla y otros productos lácteos repercuten negativamente sobre las perspectivas latinoamericanas de exportación de productos agropecuarios de clima templado.

Salvo los casos de carne bovina, maíz, cereales forrajeros y aceites y grasa, la política agrícola común ha llevado el grado de autoabastecimiento hasta la autosuficiencia y la generación de excedentes. La baja elasticidad-ingreso de la demanda de productos agropecuarios en la CEE ha sido agravada por los elevados precios relativos de esos productos derivados de los precios de orientación notablemente por encima de los niveles internacionales.

Para los productos de la agricultura tropical, los elevados impuestos internos en la CEE, como en el caso del café, restringen severamente la elevación de los niveles de consumo por habitante. Por otro lado, las preferencias otorgadas a los EAMA han creado una situación discriminatoria contra las exportaciones latinoamericanas. Con todo, salvo en el caso del cacao, las participaciones relativas para los otros productos significativos, café y banano, la posición relativa América Latina-EAMA en el mercado comunitario no ha sufrido variaciones fundamentales. La expansión de las exportaciones de los EAMA a la CEE se ha concentrado primordialmente en productos manufacturados que aumentaron su participación en el total de las exportaciones del $17 \%$ al $35 \%$ entre 1958 y 1970.

Las tendencias del comercio latinoamericano con los países miembros de la CEE debilitaron los vínculos históricos que la región mantuvo con Europa. En el pasado, el capital europeo contribuyó a financiar el desarrollo de la producción de productos primarios orientados hacia el mercado internacional y de la infraestructura física (transportes, comunicaciones) y de servicios (finanzas, seguros). Esto viabilizó, durante la etapa de "crecimiento de afuera" la vinculación latinoamericana con Europa y el resto de los países. desarrollados, fundamentalmente Estados Unidos. Al perder dinamismo las exportaciones tradicionales de América Latina, se redujeron drásticamente las inversiones europeas en la producción primaria (salvo en el sector minero, incluyendo petróleo) y en los servicios públicos. En cambio, la industrialización latinoamericana, fundamentalmente en los países de mayor mercado del área, atrajeron, como en el caso de las inversiones norteamericanas, proporciones crecientes de inversiones europeas. Sin embargo, estas inversiones en la industria, orientadas fundamentalmente hacia el mercado interno en el marco de los procesos de sustitución de importaciones, no permitieron reemplazar, sobre la base de una nueva es- 
tructura de exportaciones latinoamericanas, el papel tradicional de las inversiones europeas como instrumento de asociación comercial entre los países latinoamericanos y los países industrializados.

En relación con la corriente de ayuda externa de la CEE hacia América Latina, se mantiene en niveles muy modestos e incapaces de provocar un efecto significativo en la masa de recursos adicionales disponibles para el desarrollo latinoamericano. Por otra parte, en esta materia la CEE orienta fundamentalmente sus recursos hacia los países EAMA y los territorios que mantuvieron o mantienen relaciones de dependencia con los países miembros de la Comunidad. ${ }^{3}$

\section{La ampliación de la CEE}

La ampliación de la CEE profundizará las tendencias que registra el comercio entre ambos espacios económicos por la convergencia de la extensión de la política agrícola común de la CEE al Reino Unido, el trato preferencial otorgado a los EAMA en el mercado británico y la extensión de ese trato a los países en desarrollo del Commonwealth dentro del mercado comunitario. Estos hechos probablemente frustrarán, por lo menos en parte, el efecto positivo que cabe esperar de la aceleración de la tasa de crecimiento del Reino Unido. De todos modos, conforme a la experiencia de la CEE, esa expansión del comercio se orientará primordialmente hacia otros países industrializados antes que a los países en desarrollo, incluyendo los de América Latina y aun aquellos que mantienen relaciones especiales con la CEE.

Las exportaciones latinoamericanas de productos agropecuarios de zona templada serán desfavorablemente afectadas por la incorporación británica a la política agrícola común de la CEE. Es previsible un aumento del autoabastecimiento en el seno de la CEE ampliada y una rápida expansión de intercambio de productos agropecuarios, tal cual ocurrió en la experiencia de la CEE. En particular, la producción británica estará en condiciones de competir más ventajosamente con los abastecedores del resto del mundo, incluyendo la América Latina, dentro del mercado comunitario. Probablemente, esto incidirá de manera notable en el comercio de las carnes bovinas, aunque el efecto sobre el monto del déficit absoluto de la CEE ampliada puede ser compensado por el rápido ritmo de crecimiento de la demanda de ese producto. En grasas y aceites y

${ }^{3}$ En relación a Ia transferencia de capitales privados se registran movimientos importantes en préstamos en euro-monedas, según se analiza más adelante. 
cereales forrajeros y maíz, cabe formular una observación similar.

En el caso de productos tropicales, la competencia de los países en desarrollo que gozan de trato preferente en la GEE ampliada será particularmente apreciable en 'café soluble y cacao, situación que afectará seriamente a varios países latinoamericanos. Este efecto negativo queda atenuado, en parte, por la rebaja de derechos para el café y el cacao en la CEE. En el caso del azúcar, en lası negociaciones de adhesión, el Reino Unido hizo especial hincapié en preservar los intereses de los países adheridos al Acuerdo del Azúcar del Commonwealth, al mismo tiempo que se reiteró la importancia del Acuerdo Internacional del Azúcar.

En el plano del comercio de manufacturas, la ampliación de la Comunidad puede tener un efecto negativo sobre el sistema de preferencias generalizadas. El Reino Unido y Dinamarca están aplicando actualmente este sistema. A partir del 19 de enero de 1973, estos países e Irlanda armonizaron la aplicación del mismo con el aplicado por la CEE de 6. Pero la ampliación de la Comunidad contribuye a erosionar el efecto positivo que el sistema de preferencias generalizadas puede ejercer sobre las exportaciones de manufacturas al mercado comunitario. Al liberalizarse progresivamente el intercambio dentro de la CEE ampliada y entre ésta y Suecia, Finlandia, Suiza, Austria, Portugal e Islandia, las exportaciones de manufacturas desde los países en desarrollo hacia esos mercados dejarán de gozar del margen preferencial de que gozaban anteriormente. Si a esto se agrega la presumible reducción de los niveles de tarifas para el comercio de manufacturas, que puede surgir de la nueva rueda de negociaciones en el seno del GATT, se comprende que el margen de preferencia previsto por el sistema puede quedar seriamente reducido. En este último aspecto, la erosión real dependerá de la reducción de aranceles para los productos de mayor interés para los países en desarrollo.

En el campo de las corrientes de capital y tecnología no es previsible que la adhesión británica modifique, en un sentido u otro, la orientación de las relaciones que en este campo mantienen la GEE y la América Latina. La composición de las inversiones directas británicas en la América Latina difiere considerablemente de las de los países membros de la GEE. Aquellas están concentradas en la producción petrolera en Venezuela, Trinidad y Tobago y las Antillas Holandesas y superan los U\$S 1.000 millones. Las inversiones en bancos $\mathrm{y}$ seguros continúan siendo otro sector importante de las inversiones británicas en el área. El resto de los sectores, particularmente la industria, registran inversiones británicas menos significativas que las alemanas, francesas, italianas y holandesas, que han jugado un papel importante en el proceso de sustitución de 
importaciones en algunos países latinoamericanos, particularmente en las industrias mecánicas y químicas. Las inversiones británicas en América Latina, excluyendo petróleo, bancos y seguros, ascendían en 1968 a cerca de U\$S 600 millones, esto es, el 4,2\% del total de las inversiones directas británicas en el exterior. La adhesión británica a la CEE probablemente estimule un mayor interés en inversiones en áreas distintas a las tradicionales, en la medida en que se produzcan fusiones y combinaciones entre empresas de ese país y del resto de la CEE. De todos modos, esto depenclerá del fortalecimiento de la balanza de pagos del Reino Unido y de las políticas que los países latinoamericanos sigan en relación a la inversión extranjera directa.

\section{II. - EL ENGUADRE DE LAS RELAGIONES AMÍRIGA LATINA-CEE $Y$ SUS PERSPEGTIVAS}

\section{Comercio y transferencia de recursos: tendencias}

Las relaciones entre la CEE y la América Latina, como las del conjunto de los países avanzados con el mundo desarrollado, están fundadas en las tendencias concretas de la realidad más que en valores apoyados en consideraciones éticas. Como ha dicho recientemente el Canciller Brandt, el hombre no ha aprendido aún a ayudar al hombre. Cierto es que desde hace varios Iustros, en el seno de los países avanzados, se presta atención creciente a los problemas del mundo en desarrollo y se afianzan los criterios apoyados en la solidaridad del género humano y en la unidad de su experiencia en un mismo planeta. Pero estas consideraciones sólo se han reflejado muy débilmente en la marcha de las relaciones económicas entre los países avanzados y el mundo en desarrollo durante el último cuarto de siglo.

Pocos indicadores bastan para ilustrar el punto. La transferencia neta de recursos comprendida en la Ayuda Oficial para el Desarrollo en 1972 álcanzó a 8.600 millones de dólares y se orientó a países con una población total de 1.900 millones de habitantes. Lá ayuda por habitante se ubicó, por lo tanto, en 4,40 dólares por persona. Desde 1962 este valor disminuyó en $10 \%$ en térninos reales. La AOD sólo representó en 1972 el 0,34 del producto nacional bruto de los países miembros del Comité de Ayuda al Desarrollo de la OCDE. Se comprende que la dimensión de esta ayuda para países que representan más del $60 \%$ de la población mundial (exclu- 
yendo los países asiáticos con economía centralmente planificada) y cuentan con un ingreso medio por habitante de 200 dólares $^{4}$, sólo implica una contribución marginal al problema fundamental del subdesarrollo que afecta a la mayor parte del género humano. ${ }^{5}$

Por otra, parte, aun sin entrar a considerar la significación de la inversión privada directa sobre el desarrollo de los países de la periferia, se advierte que las inversiones de este tipo desde los países avanzados hacia el Tercer Mundo alcanzó en 1972 a 3.800 millones de dólares, que probablemente equivale al $20 \%$ del monto total de las inversiones privadas de las corporaciones privadas que operan en escala internacional. Estas inversiones se realizan fundamentalmente entre países avanzados. Considerando las de origen norteamericano, que representan alrededor del $70 \%$ de las mundiales, se observa que en 1970 las radicadas en los países en desarro110 ascendían al $27,4 \%$ de las inversiones privadas directas totales con tendencia declinante (en la década de 1960 aquellas representaron el 22,3\% del incremento de esas inversiones).

En relación a la transferencia de tecnología, los Estados Unidos que reciben el $60 \%$ de los pagos mundiales en concepto de regalías, perciben la mayor parte de esos pagos desde Europa, Canadá y Japón, es decir, desde otros países desarrollados.

Las transferencias de recursos de capital y tecnología desde los países avanzados hacia las economías en desarrollo constituyen, por lo tanto, una parte menor de las transacciones mundiales en esos conceptos que, crecientemente, se realizan dentro del bloque de países avanzados.

En materia comercial, conforme se señaló en el apartado anterior, las tendencias son similares. El proceso de liberación comercial registrado en el seno del GATT sirvió fundamentalmente para promover el intercambio de manufacturas y las transacciones entre los países avanzados. En la Rueda Kennedy se logró una reducción ponderada del $33 \%$ de las tarifas sobre productos industriales y las concesiones recíprocas abarcaron intercambios por más de $40.000 \mathrm{mi}$ llones de dólares. Los productos agropecuarios, de principal interés para los países en desarrollo, quedaron prácticamente fuera del ámbito de las negociaciones. Como es Iógico, la orientación de la liberación del comercio internacional reflejó las tendencias reales del comercio y la economía mundiales.

${ }^{4}$ Dato para 1969 equivalente a menos del $8 \%$ del ingreso medio de los países avanzados.

${ }^{5}$ O.C.D.E.: Policy perspectives for international trade and economic development, París, 1972. Informe del DAC para 1972. 


\section{La Rueda Nixon y las negociaciones monetarias}

En el plano del comercio se ha avanzado significativamente en la identificación de los problemas de los países en desarrollo, particularmente a través de las reuniones de la UNCTAD. En la Declaración aprobada en la Reunión Ministerial del GATT en Tokio en septiembre último, se presta preferentemente atención a los problemas del mundo en desarrollo. Se dice que las negociaciones estarán encaminadas a "un mejoramiento sustancial de las condiciones de acceso de los productos de interés para los países en desarrollo y, cuando sea pertinente, la adopción de medidas encaminadas a lograr unos precios estables equitativos y remuneradores para los productores primarios". Se incluye entre los objetivos de las negociaciones el tratamiento del sector agropecuario y de los productos tropicales. Se acepta el principio de la no reciprociclad para las concesiones que puedan recibir los paises en desarrollo y se afirma. que "Ios Ministros reconocen la necesidad de adoptar en las negociaciones medidas especiales para ayudar a los países en desarrollo en sus esfuerzos por aumentar sus ingresos de exportación y promover su desarrollo económico y de, cuando proceda, prestar atención prioritaria a los productos o sectores de interés para los países en desarrollo". Se sostiene también la importancia de mantener y mejorar el Sistema Generalizado de Preferencias y la de aplicar medidas diferenciadas a los países según modalidades que les proporcionen un trato especial y más favorable en los sectores de negociación donde sea posible y apropiado. En la Declaración se toma nota también de las necesidades especiales de los países menos adelantados dentro de los países en desarrollo y de la importancia de un trato especial para los mismos en el contexto de las medidas que se adopten en favor de los países en desarrollo.

Los avances logrados en el reconocimiento de los problemas comerciales de la periferia en la Declaración de Tokio son realmente importantes. Sin embargo, es muy probable que el resultado concreto de las negociaciones continúe reflejando las necesidades de la expansión del comercio entre los propios países avanzados. Los hechos tienen más vigencia que las declaraciones. Las negociaciones sobre tarifas y barreras no tarifarias probablemente se concretarán en las cuestiones de interés primordial para los países y grupos dominantes en el comercio mundial como la CEE, los Estados Unnidos y Japón. En el campo agrícola el comportamiento del comercio y los precios en el curso de 1973 puede estimular una negociación más activa tendiente a estabilizar corrientes de intercambio y precios $y$ ten- 
drán como un elemento fundamental el interés de los Estados Unidos de acceder al mercado de la CEE. Las negociaciones en torno del artículo 19 del GATT relativo a las cláusulas de salvaguardia será de importancia para los países en desarrollo pero su interés primordial es para liberar obstáculos al comercio entre países avanzados. En cuanto al Sistema Generalizado de Preferencias, su importancia puede quedar debilitada por el mismo proceso de reducción de tarifas de los países avanzados y, en todo caso, su vigencia quedará definida en 'la medida en que se aplique a productos de especial interés para los países en desarrollo, incluyendo los intensivos en mano de obra. De todos modos, una evaluación realista del SGP revela que su aporte a la expansión de las exportaciones de los países en desarrollo hacia los mercados de las economías avanzadas es marginal y, en todo caso, se vincula a otras medidas para promover el comercio.

No cabría esperar de la Rueda Nixon impulsos fundamentales a las exportaciones desde los países en desarrollo, aunque su contribución en este sentido puede ser significativa. En última instancia son la composición de las exportaciones de esos países $y$ las tendencias de integración entre las economías avanzadas, los factores que han venido marginando al mundo en desarrollo de las corrientes más dinámicas del comercio mundial. Y esto encuadra, también, las relaciones entre la CEE y la América Latina que constituyen un aspecto de las relaciones globales entre el mundo desarrollado $y$ Ios países en desarrollo. Inclusive en el plano de la reforma monetaria internacional, se advierte que las posibilidades efectivas de vincular la creación de liquidez a la transferencia de recursos hacia la periferia, esto es el problema del vínculo entre la creación de los derechos especiales de giro y la ayuda al desarrollo, son limitadas y la posición de algunos importantes países avanzados francamente opuesta al esquema. En última instancia, la reforma del sistema monetario internacional obedece, también, a la necesidad de eliminar los obstáculos que las recurrentes crisis monetarias imponen a las relaciones entre los países avanzados. Cierto es que todos los avances para facilitar la expansión del comercio mundial, un crecimiento sostenido de los países industriales y la formación de un sistema monetario estable, favorece también a los países en desarrollo al expandir sus mercados y eliminar las bruscas oscilaciones a que están sujetos sus ingresos de exportación. Pero, al mismo tiempo, no puede ignorarse que la reforma es prioritariamente una necesidad del proceso de interdependencia creciente entre los países avanzados en las nuevas condiciones impuestas por el cambio de las posiciones relativas de los principales países y el necesario restablecimiento del equilibrio en el balance de pagos norteamericano. 
Los reajustes de las paridades cambiarias han contribuido a este último objetivo pero constituyen una herramienta insuficiente para el ordenado funcionamiento del sistema monetario y de las relaciones económicas internacionales.

Parece bastante claro que las importantes negociaciones en curso en el plano comercial y monetario tienden fundamentalmente a transar los conflictos dentro del mundo desarrollado y a eliminar los obstáculos que se oponen a su interdependencia creciente. Es un hecho significativo de este último proceso que, en el marco de un notorio desorden en el sistema monetario internacional (con cambios frecuentes de paridades de varias monedas principales, inclusive del dólar que constituye el principal activo de reserva internacional, y de cuantiosos movimientos especulativos de capital de corto plazo), el comercio internacional se está expandiendo a tasa sin precedentes y los países avanzados registran un aumento sustancial de la actividad económica, los ingresos reales y el empleo. Las políticas expansivas de los países avanzados, aun en el marco de una aguda crisis del sistema monetario internacional, permitió un rápido aumento de la producción. Después de un bajo aumento del $3,5 \%$ en 1971 sobre 1970 , la tasa de crecimiento aumentó al $5,5 \%$ en 1972 y, entre el segundo semestre de 1972 y el primero de 1973, la tasa superó el $7 \%$. La misma tendencia expansiva se observa en el comercio mundial. Su volumen creció en más del $8 \%$ entre 1971 y 1972 para ubicarse cerca del promedio de crecimiento de la década de 1960 y superar la baja tasa del $5,5 \%$ registrada en 1971. En el primer semestre de 1973 la tasa se ubicó en el $12 \%$ sobre el mismo período del año anterior ${ }^{6}$. Las principales corrientes de intercambio, conforme a la experiencia del último cuarto de siglo, se registran entre los mismos países avanzados.

La capacidad expansiva de esos países avanzados y las tendencias a su interdependencia creciente superan los obstáculos impuestos por los desajustes monetarios.

\section{Las prioridades de la GEE}

En este contexto parece bastante claro que las relaciones con los países en desarrollo, incluyendo las de la CEE con la América Latina, no figuran entre las primeras prioridades de los países avanzados. En el caso de la CEE los problemas principales que pretenden resolverse son el avance hacia la segunda etapa de la Unión económica y monetaria y el cumplimiento de los objetivos de la

'F.M.I., Informe Anual, 1973. 
reunión de los jefes de Gobierno de los países comunitarios en $\mathrm{Pa}$ rís el año pasado. Los obstáculos surgidos en el cumplimiento de la primera etapa del proceso y los problemas que plantea la ausencia de la libra y la lira del sistema de flotación conjunta frente al dólar, han llevado a varios gobiernos a formular interrogantes sobre la viabilidad de los plazos trazados. Por otra parte, existen reparos por parte de los Países Bajos de confiar a los organismos e instituciones europeos más responsabilidades importantes en materia económica y monetaria, si paralelamente no se establece un sistema de control democrático sobre esas instituciones y organismos; el fortalecimiento del Parlamento Europeo es, desde ese punto de vista, un requisito previo al avance de la Unión económica y monetaria. La CEE enfrenta otros problemas de significativa importancia. Entre ellos la consolidación de la expresión comunitaria en la política internacional conforme a la decisión de los Nueve en la reunión de Copenhague. La formulación de esta posición comunitaria en las previstas reuniones con el Presidente de los Estados Unidos es un tema prioritario en el proceso de la unidad europea. La política regional, el programa de acción social europea y, "last but not least", la revisión de la política agrícola común constituyen temas también prioritarios en la atención de los países miembros de la CEE. ${ }^{\mathrm{T}}$

En materia de política exterior, la definición de la posición frente a los Estados Unidos en las relaciones bilaterales y en el plano de la política internacional y de las negociaciones comerciales y monetarias, es un área de primera prioridad para la CEE.

Más allá de las propias fronteras de la GEE, la Comunidad se encuentra empeñada en consumar su proyecto europeo a través de la consolidación de los vínculos con los antiguos miembros de la Asociación Europea de Libre Comercio que no han pasado a ser miembros de la Comunidad ampliada. Los acuerdos logrados con estos países - Austria, Islandia, Portugal, Suecia y Suiza- a mediaclos de 1972 prevén el mantenimiento de la eliminación de los derechos de aduana para los productos industriales entre ellos y los viejos miembros de la AELC, Dinamarca y el Reino Unido, y, por otra parte, su supresión gradual en las relaciones con los seis miembros de la Comunidad primitiva e Irlanda. Finlandia y Noruega se incorporan posteriormente a estos arreglos. Estos países europeos se caracterizan por intercambios comerciales intensos con la GEE, absorbiendo el $23 \%$ del conjunto de las exportaciones co-

TOtras áreas importantes son la política energética (cuya prioridad ha sido acrecentada por el conflicto de Medio Oriente), la política industrial y científica, la protección de medio ambiente, la política de transporte y la determinación de las normas sobre la competencia. 
munitarias; la CEE ampliada representa entre $31 \%$ (Islandia) y $54 \%$ (Noruega) de sus propias exportaciones, mientras que los niveles alcanzados respecto de la Comunidad de 6 iban del $17 \%$ (Islandia) a $39 \%$ (Austria).

\section{a) La Cuenca del Mediterráneo}

Los países de la Cuenca del Mediterráneo constituyen otra área vital del proyecto europeo. Descle 1958 se han venido firmando acuerdos de asociación con Grecia, Turquía, Malta, Chipre, Marruecos y Túnez. Se han firmado también acuerdos comerciales preferentes con España, Israel, Egipto y el Líbano. Con Yugoslavia existe un acuerdo no preferente $y$, con Portugal, miembro de la AELC, se ha firmado un acuerdo para la constitución de una zona de libre comercio en el marco de los tratados firmados con los países miembros de esa entidad a que se hizo referencia anteriormente. Dentro de la Cuenca sólo Libia y Siria no han establecido acuerdos especiales con la CEE.

Está prevista la plena adhesión de Grecia y Turquía a la CEE y los acuerdos con Malta y Chipre prevén el establecimiento de una unión aduanera. La Cuenca Mediterránea constituye un espacio histórico de influencia europea. Los países de la Cuenca absorbían en 1972 alrededor del $15 \%$ de las exportaciones de la CEE de $6 \mathrm{y}$ el intercambio entre ambos espacios económicos ha venido creciendo a tasas vecinas al $10 \%$ anual. A su vez, los países de la Cuenca realizan alrededor del $50 \%$ de su intercambio total con la CEE.

Las exportaciones de la CEE hacia los países mediterráneos están compuestas, principalmente, por productos industriales, básicamente material de transporte, bienes de capital y otros bienes de la industria mecánica. Sus importaciones están formadas en alrededor de un $30 \%$ por productos agrícolas (fundamentalmente aceite de oliva, vino, cítricos, frutas y legumbres), un $40 \%$ de petróleo crudo $y$ el resto, principalmente, por manufacturas livianas. En el tipo de productos agrícolas que importa de la Cuenca, ésta representa alrededor del $80 \%$ del abastecimiento extra-GEE. Pero es especialmente en petróleo donde el espacio mediterráneo juega un papel fundamental en las relaciones externas de la CEE. Dentro de la zona, Libia y Argelia proporcionan, prácticamente, la totalidad de las exportaciones de petróleo a la CEE.

La Comunidad es fuertemente deficitaria en materia petrolera, que en las condiciones europeas equivale a decir en materia energética, a lo cual debe agregarse la significación del petróleo para 
la industria petroquímica. La CEE, junto con el Japón, constituyen los únicos dos grandes espacios económicos industrializados con un agudo déficit petrolero.

El déficit petrolero de la $\mathrm{CEE}$, en 1970, ascendió a 670 millones de toneladas y se estima que éste se duplicará para 1980. Alrededor de un tercio de dicho déficit es cubierto por las importaciones de petróleo desde Argelia y Libia. Así se explica que un observador sostenga que "la vía de desarrollo del Mediterráneo pasa por el petróleo".

El espacio mediterráneo sostiene también un activo tráfico de personas con la CEE. Se estima que alrededor de 3 millones de trabajadores en la Comunidad, esto es, cerca de un $5 \%$ del total de la fuerza de trabajo, proviene de países mediterráneos. Por otra parte, las corrientes turísticas desde la CEE se orientan fundamentalmente hacia los países de la Cuenca, generando un flujo de recursos de alrededor de U\$S 3.000 millones anuales. Esto, sumado a las remisiones de los trabajadores radicados en la CEE, constituye una corriente de recursos equivalente a más del $50 \%$ del total de las exportaciones mediterráneas a la CEE.

\section{b) La apertura a los paises del Este de Europa}

El proyecto de la CEE se integra con la apertura a los países del Este de Europa. El comercio de la CEE de 6 con los países europeos del COMECON pasó de 1.700 millones en 1958 a 6.600 millones en 1971 pero continúa presentando una proporción relativamente baja del comercio exterior comunitario. En 1970 sólo alcanzaba al $6,3 \%$ de los intercambios de la CEE de 6 . Como se sostiene en un reciente documento de la CEE: "geográfica, histórica y culturalmente, Europa no termina en Berlín, Viena y Trieste"s. Las relaciones entre la CEE y los países del Este de Europa han venido avanzando firmemente. A principios de este año la Unión Soviética reconoció la entidad comunitaria y desde prácticamente la misma época es la Comisión de la CEE la que, tomando las orientaciones recibidas del Consejo, conducirá en el futuro las negociaciones con los países del Este, es decir cuando expiren los acuerdos actualmente vigentes negociados sobre bases bilaterales entre países de la CEE y del Este de Europa. Los vínculos entre ambos espacios económicos están íntimamente vinculados a los acuerdos políticos y de seguridad que se están negociando en la Conferencia sobre la Seguridad Europea y los avances en esta área ampliarán el ámbito de

${ }^{8}$ La Comunidad y sus vecinos, Comunidad Europea, Bruselas, octubre 1973. 
los intercambios económicos. Como se señala en el documento recién citado, estos abarcan no sólo la expansión del comercio sino corrientes financieras y tecnológicas intimamente asociados a los acuerdos comerciales.

La expansión de las economías del Este de Europa genera una activa corriente de importaciones de bienes de capital y de consumo. Esas economías constituyen ya un mercado importante para algunos sectores: textiles, construcciones navales, máquinas eléctricas, instalación de fábricas llave en mano, etc. Una restricción al intercambio sigue siendo el hecho de que los países del Este exporten principalmente a la $\mathrm{CEE}$ productos básicos -materias primas, productos energéticos y agrícolas- fuertemente sujetos a la evolución de la actividad económica de la CEE. Este escaso grado de complementaridad, sobre todo al nivel de la producción industrial y el intercambio de manufacturas, junto a la inconvertibilidad de las monedas de los países del Este actúan como factores limitativos del intercambio. Las perspectivas son, sin embargo, de una rápida expansión del comercio y las transacciones financieras y tecnológicas entre ambos espacios económicos.

\section{c) El Acuerdo de Yaundé}

Más allá del espacio europeo y de la Cuenca Mediterránea, las relaciones de la CEE con las ex colonias africanas constituye un campo prioritario de las relaciones externas de la CEE. A ellas se agregan numerosos países miembros de la Comunidad Británica de Naciones a partir de la adhesión del Reino Unido a la CEE.

Las relaciones entre la Comunidad y las ex colonias africanas quedaron formalizadas en el primer Convenio de Yaundé, de julio de 1963. Este Convenio sucedió a otro quinquenal entre los mismos países, más Guinea, época en la cual varios de los países signatarios no se habían independizado aún. En 1969, se renovó el Convenio de Yaundé con validez por cinco años desde el 10 de enero de 1971. La población de los Estados Africanos y Malgache (EAMA) asciende a 70 millones de habitantes.

Los países africanos signatarios del mencionado convenio representaban, en 1970, el 4\% del comercio exterior de la CEE. Las importaciones comunitarias desde esos países se componían en alrededor de un tercio de cobre $y$ mineral de hierro; $20 \%$ de café y de cacao y algo más de un tercio de manufacturas livianas. Esas importaciones representaban en 1970 un $12 \%$ de las importaciones totales de la CEE desde países en desarrollo. Entre 1958 y 1970 , las importaciones provenientes de los EAMA crecieron en un $104 \%$, 
comparado con el $183 \%$ de todas las importaciones extra-CEE y el $136 \%$ de las provenientes de todos los países en desarrollo. Consecuentemente, la participación de Ios EAMA en el mercado comunitario bajó entre 1958 y 1970 del $5,7 \%$ al $4 \%$ para el total de las importaciones extra-CEE, y del $13,4 \%$ al $12 \%$ para las provenientes de todos los países en desarrollo.

El Convenio de Yaundé dispone la formación gradual de una zona de libre comercio entre la GEE y cada uno de los 18 países africanos signatarios, un sistema de ayuda financiera y técnica y la creación de instituciones encargadas de administrar y orientar el Convenio. La mayor parte de los productos de los EAMA entran en la CEE libres de derechos aduaneros desde el 1 \% de julio de 1968 y los productos agrícolas sujetos a la política agrícola comunitaria son tratados caso por caso, gozando, de todos modos, de un trato diferente con respecto a terceros países. El Convenio establece un sistema de preferencias recíprocas según las cuales los países de la CEE gozan de un trato arancelario preferente en los mercados de los EAMA y de la no. aplicación de cuotas, sin perjuicio de la protección necesaria para proteger las "industrias macientes".

La ayuda financiera de la CEE a los EAMA se canaliza a partir de 1958 a través del Fondo Europeo de Desarrollo. Entre 1958 y 1969 la ayuda bruta canalizada por esta vía ascendió a U\$S 1.381 millones, de la cual alrededor del $90 \%$ corresponde a subsidios. De ese total, U\$S 70 millones se destinaron a los territorios africanos que mantienen una relación de dependencia con países miembros de la CEE y a los cuales ésta le ha extendido un trato arancelario preferencial. Conforme al segundo Convenio de Yaundé los Recursos del Fondo fueron aumentados en U\$S 1.000 millones (de los cuales U\$S 82 millones destinados a las posesiones africanas). El $90 \%$ de estos recursos continuarán asignándose en forma de subsidios.

Otros países africanos (Kenia, Uganda y Tanzania), firmaron en Arusha un Convenio de Asociación con la Comunidad, en julio de 1968, renovado en septiembre de 1969, que establece un régimen comercial similar al del Convenio de Yaundé, pero no prevé asistencia financiera.

La adhesión del Reino Unido a la CEE implica la terminación del régimen de preferencia establecido en la Conferencia de Ottawa de 1932, en el cual se apoyaban las relaciones económicas dentro de la Comunidad Británica. En el caso de los países desarrollados del Commonwealth, Australia y Canadá, se consuma así el progresivo deterioro de la importancia relativa del vínculo con el Reino Unido. En el caso de Nueva Zelandia, el Reino Unido negoció con la CEE; a satisfacción de los neozelandeses, arreglos especiales transitorios para productos lácteos y carnes ovinas. In el caso de lo grandes países 
en desarrollo de Asia, India y Pakistán, Ceilán y Malasia, no se prevén vínculos especiales con la CEE ampliada, más allá de la aplicación del sistema de preferencias generalizadas y el compromiso de la CEE de analizar con ellos los problemas comerciales que puedan surgir. La misma situación regirá para Hong Kong y Singapur. Esto, sin perjuicio de la vigencia de algunos acuerdos especiales sobre ciertos productos, como los firmados entre la CEE y la India sobre artesanías y productos de coco y con Pakistán sobre productos de yute.

En cambio, los restantes países en desarrollo independientes del Commonwealth, del Africa, del Caribe y de los Océanos Indico y Pacífico podrán optar por adherencia a una renovación del Convenio de Yaundé, a alguna otra forma de asociación como la del Convenio de Arusha o el establecimiento de acuerdos comerciales preferenciales. La decisión deberá tomarse, a más tardar, el lo de febrero de 1975, manteniéndose hasta entonces los vínculos vigentes con el Reino Unido. A su vez, los territorios dependientes podrán asociarse a la CEE bajo la Sección IV del Tratado de Roma.

La adhesión británica a la CEE implica, por lo tanto, una ampliación considerable de la Política de la GEE de establecer vínculos especiales con países y territorios que mantuvieron o mantienen relaciones de dependencia con las naciones que forman parte de la Comunidad. En total, cerca de 70 países en desarrollo participarán ahora del régimen especial de vinculación con la CEE, cuya versión más significativa es el Convenio de Yaundé. Al mismo tiempo, los vínculos actualmente existentes entre los países signatarios de los convenios de Yaundé y Arusha y la CEE se extenderán ahora al Reino Unido y a los países candiclatos a la adhesión.

De hecho, varios países del Commonwealth ya habian establecido vínculos especiales con la CEE, como en el caso cle los signatarios del Convenio de Arusha. A su vez, clentro del espacio mediterráneo, Malta y Chipre tienen acuerdos para el establecimiento de la unión aduanera con la CEE.

\section{Hechos y valores en las relaciones GEE-América Latina}

Las tendencias actuales de la GEE revelan que existen en, la política exterior de la Comunidad prioridades más urgentes que las relativas a sus vínculos con el mundo en desarrollo. Lo mismo puede decirse de la política exterior de los Estados Unidos en que sus polos dominantes son el entendimiento con la Unión Soviética y China y la transacción de sus diferencias con la CEE y Japón. El actual conflicto del Medio Oriente puede concebirse como un caso especial 
de las relaciones entre las grandes potencias. Japón es, probablemente, el único de los grancles países industriales para el cual sus relaciones con los países en desarrollo se ubica entre sus primeras prioridades. La razón es clara. Ese país depende en medidas sustanciales del suministro de alimentos y materias primas provenientes de Ios páses en desarrollo y, a diferencia del caso de los otros grandes países industriales, las importaciones japonesas de productos primarios y desde los países en desarrollo ha crecido al mismo ritmo que el conjunto de sus importaciones.

Estos hechos tienen una profunda significación para la América Latina. Es vital para los países de la región tomar en cuenta las tendencias de la economía contemporánea y asumir el hecho, sostenido como hipótesis en este informe, que sus relaciones con la CEE y el resto del mundo desarrollado estará más influido por esas tendencias que por consideraciones éticas incorporadas en las políticas de los países avanzados.

Las relaciones económicas externas de los países avanzados se apoyan en criterios de rentabilidad privada.

Las corrientes de comercio y de inversiones se fundan, naturalmente, en el rendimiento de las mismas. Lo mismo ocurre al nivel de las políticas nacionales cuando se procura, por ejemplo, abrir nuevos mercados, promover las exportaciones, controlar recursos naturales en el exterior o participar en la producción en otros mercados. En este contexto, los cambios en la composición de la demanda por las distintas elasticidades ingreso de las manufacturas y de los productos primarios, y por las orientaciones del progreso técnico, son determinantes en la economía internacional de la formación de los vínculos entre países. Si se admitieran, además, criterios de rentabilidad social la naturaleza de esos vínculos podrían cambiar considerablemente. Entonces, se justificarían en relación a los países en desarrollo, por ejemplo, la transferencia de recursos a largo plazo y a bajo costo, y la apertura de los mercados internos de productos agropecuarios. E1 efecto que esto produciría en cuanto a bienestar en el plano internacional y su repercusión posterior en la expansión del comercio, convertiría esas medidas, apoyadas originariamente en criterios de rentabilidad social, en factores ulteriores de rentabilidad "privada" para los países avanzados y sus empresas. Criterios de este tipo son los que, a nivel nacional, sustentan, por ejemplo, los programas de desarrollo regional para las zonas rezagadas. Esos mismos criterios se proyectan al plano multinacional, en el caso de la GEE, a través de la política comunitaria de desarrollo regional y las políticas del Banco Europeo de Inversiones no sólo en ese aspecto, sino también en el del desarrollo de la infraestructurạ y la reorganización y modernización industrial. 
La proyección externa de la CEE refleja, en último análisis, las posiciones de poder, los intereses y los valores predominantes; en síntesis, los esquemas políticos de los países de la Comunidad. EI escenario europeo actual revela que esos esquemas políticos están siendo fuertemente controvertidos y que se encuentran en proceso de cambio. Guestiones tales como la democratización del poder económico; la participación popular en la conducción del Estado, los centros de decisión económica y las unidades productivas; el cuestionamiento de los valores de la sociedad de consumo y del desarrollo por el desarrollo mismo; la crítica a los resultados económicos y éticos, en términos de la calidad de la vida, de los sistemas económicos vigentes; la lucha por el acceso a la cultura y la educación como instrumento fundamental de la justicia distributiva; están hoy activamente presentes en los planos políticos e ideológicos en la CEE. Estas tendencias pueden llegar a influir profundamente en el comportamiento hacia el exterior de la Comunidad, en la medida en que lleguen a incorporarse en sus políticas valores de mayor trascendencia, asentados en principios éticos y en perspectivas de largo plazo, que sustituyan los criterios a corto plazo de rentabilidad que han tenido una influencia dominante hasta el presente. Si esto ocurre, es factible, aunque no previsible en el corto plazo, un cambio profundo de la política de la CEE con respecto a los países en desarrollo y el asentamiento de la política de cooperación con otros países, particularmente dentro de la zona influencia de la CEE, sobre bases nuevas. Esto viabilizaría una transferencia importante de recursos dentro de un proyecto de coparticipación efectiva en la superación del subdesarrollo, distinto del tradicional modelo de asociación colonial o, en términos más generales, de centro-periferia.

De todos modos, no debe aducirse que esta modificación de la política externa de la Comunidad surja necesariamente del proceso de cambio político y debate ideológico actualmente en curso. Por el contrario, dentro de las nuevas ideas y del cuestionamiento de las situaciones establecidas, se advierten corrientes de pensamiento, en relación a los países en desarrollo, que tienden a consolidar la división del mundo en países desarrollados y países atrasados. En las discusiones sobre medio ambiente, la calidad de la vida y los aspectos negativos del desarrollo se advierte, con frecuencia, una tentativa de congelar la situación en su estado actual, que dista, por cierto, de ser satisfactorio para los países en desarrollo. ¿Cómo puede pensarse, sin desconocer en el fondo la situación de atraso que aqueja a la mayor parte del género humano, en la conveniencia de una reducción de la tasa crecimiento como solución para los países avanzados cuando su expansión continuada, junto a una estrecha poli- 
tica de cooperación internacional, son condiciones fundamentales para enfrentar el atraso en el resto del mundo?

Resulta indispensable, por lo tanto, identificar dentro de las tendencias de la economía mundial cuáles son las que permiten a la América Latina profundizar sus vínculos externos y ensanchar el horizonte de su propio desarrollo. Al mismo tiempo, es vital asumir la capacidad interna de desarrollo y transformación de los países latinoamericanos como condición clave de la superación del atraso -y del establecimiento de los vínculos con el mundo desarrollado sobre nuevas bases. Desde este último punto de vista podría decirse - para el caso latinoamericano, que la primera prioridad radica en la capacidad de integración interna, de movilización de los propios recursos y de establecer modelos políticos estables que encuadren el proceso de desarrollo y cambio social. A partir de aquí se dan las condiciones necesarias para una expansión de los vínculos externos y su transformación.

En ambos campos: tendencias de la economía mundial y capacidad interna de la América Latina para el desarrollo, las condiciones han cambiado radicalmente en los últimos años, $y$, en conjunto, en un sentido favorable para el desarrollo económico y social en los países del área.

\section{Aspectos positivos del contexto externo}

Se han enfatizado. en páginas anteriores las orientaciones negativas que sobre el comercio exterior de la América Latina impusieron las tendencias del comercio mundial de productos primarios y la formación de un nuevo sistema de división del trabajo entre los países avanzados al nivel del intercambio de manufacturas. Pero, simultáneamente, la economía internacional presenta en tiempos recientes una serie de tendencias que son propicias para la profundización de los vínculos externos cle la América Latina fuera de los moldes tradicionales. No podrían analizarse aquí con detenimiento esas tendencias pero conviene señalar algunas de ellas. Por un lado, la reciente mejora de los precios de productos primarios y la reactivación del intercambio en algunos rubros como carnes y cereales forrajeros, sumados a otros que conservan dinamismo, como el petróleo, pueden estai insinuanclo una rectificación de la tendencia. predominantemente en el último cuarto de siglo al deterioro de la participación de esos productos en el comercio internacional. Esta. inversión de la tendencia parece bastante probable en productos como los señalados. En este caso, varios países latinoamericanos verían acrecentados sus ingresos por la vía de la exportación de productos 
primarios. Además, algunos países se están incorporando al comercio de ciertos productos primarios, como es el caso de Ecuador en petróleo y de Brasil en soya. En resumen, parece previsible la reactivación del comercio en varios rubros primarios.

Por otra parte, la consolidación del desarrollo y la gravitación internacional de la CEE y Japón implica la formación de varios centros de poder económico y tecnológico que comparten con los Estados Unidos posiciones claves en la economía internacional. Este fenómeno de la multipolaridad amplía notoriamente la capacidad negociadora externa de los países de la América Latina.

Además, las tendencias generalizadas en el Tercer Mundo en cuanto al trato de las inversiones directas de las grandes corporaciones multinacionales, están provocando en estas una mayor flexibilidad en sus políticas operativas. Esquemas como el de la Decisión 24. de la Comisión del Acuerdo de Cartagena que, en su momento, generaron serias resistencias en círculos financieros de los países avanzados, están siendo ahora aceptados con más amplitud y sientan las. bases para un nuevo trato entre las corporaciones multinacionales y los países sede, según el cual estos últimos logran un mayor control en la decisión de las inversiones y de las estrategias de desarro1lo. La nueva ley de inversiones extranjeras en la Argentina es un acontecimiento dentro de la misma tendencia. En otras áreas, el fenómeno, probablemente, más espectacular es la renegociación generalizada de las condiciones en que operan las empresas petroleras internacionales en el Medio Oriente. Todos estos hechos tienen una enorme trascendencia porque abren nuevas puertas, sobre bases más estables, para la transferencia de capital y tecnología a través de inversiones privadas en los países latinoamericanos. Se conjugan así los objetivos de la independencia económica con la de captación de recursos adicionales del exterior. La generalización de acuerdos de joint-venture y de coproducción y la revisión de las normas para la transferencia de tecnología a la América Latina, son manifestaciones concretas de las tendencias apuntadas.

En el campo financiero se advierten también algunos desarrollos que amplían la disponibilidad de recursos para la América Latina y la flexibilidad de sus términos: Esto último se refiere, por ejemplo, a las prácticas operativas de los organismos internacionales de crédito $y$, también, a las inversiones de capital privado de cartera. En este último sentido uno de los acontecimientos recientes de especial interés es el desarrollo del mercado de euromonedas. Según cálculos extraoficiales, Ios países en desarrollo obtuvieron en el mercado de euromonedas préstamos brutos por alrededor de 8.000 millones de dólares en 1972. Como los reembolsos de estos préstamos son todavía bajos ese monto debe asemejarse al de préstamos netos. Es 
decir, que estas operaciones se acercan ya al del conjunto de las transferencias de la Ayuda Oficial para el Desarrollo y triplica la canalizada a través de los organismos internacionales de fínanciamiento. El mercado de euromonedas se ha expandido recientemente bajo la influencia de una serie de hechos convergentes, entre ellos, los considerables reembolsos de préstamos efectuados por bancos de los Estados Unidos y nuevas inyecciones de fondos provenientes de instituciones japonesas y de los países productores de petróleo. $\mathrm{El}$ aumento de la liquidez en ese mercado, frente a la retirada de reconocidos prestatarios europeos debido al recrudecimiento de los controles de capital en ciertos países, ha intensificado la competencia entre los prestamistas y permitido a los países en desarrollo movilizar importantes recursos adicionales ${ }^{\ominus}$. Como se señala en el citado informe, las ventajas de las operaciones en euromonedas derivadas de su simplicidad administrativa, de no estar "atadas" a fuentes determinadas de suministro de equipos y de la posibilidad de pasar de unas monedas a otras, deben sopesarse con los riesgos implícitos en las prácticas institucionales y en los problemas que plantea a la administración de la deucla en virtud de sus plazos relativamente breves de amortización y las fluctuaciones de las tasas de interés, conforme a la evolución del mercado: Es probable que estos préstamos hayan sustituido a otras fuentes tradicionales, como préstamos de proveedores que disminuyeron en $28 \%$ en 1972.

La ampliación de la disponibilidad de recursos financieros del exterior, junto a la aceleración del proceso de formación de capital en algunos países latinoamericanos, explica el notable incremento de la entrada de capitales autónomos en alrededor del $50 \%$ en 1972 sobre el año anterior y alcanzó los 7.500 millones de dólares. Este proceso refleja primordialmente lo sucedido en Brasil en que la afluencia neta de capital extranjero en 1972 alcanzó a 3.700 millones de dólares - aproximadamente en $80 \%$ más que en 1971- que permitió aumentar en 2.300 millones de dólares las reservas internacionales del país y contribuyó a financiar el déficit en cuenta corriente. México, Venezuela y Colombia también recibieron entradas importantes de capital autónomo. La Argentina, país en que el proceso de inversiones se viene debilitando desde mediados de 1971, registró, en cambio, una salida neta de capital autónomo por segundo año consecutivo.

\section{Aptitud latinoamericana para el desarrollo}

Estas tendencias favorables en el contexto externo son simultáneas ${ }^{\circ}$ C.F.I., El clima para las inversiones en 1972-73, Informe Anual, 1973. 
con la mayor madurez alcanzada por las economías latinoamericanas y el medio político-social. La región, en su conjunto, tiene ya un importante potencial de acumulación derivado de ingresos medios en torno de los 600 dólares anuales por habitante y de respetables coeficientes de ahorro que se acercan al $20 \%$ y financian el $90 \%$ de las inversiones totales. Al mismo tiempo, se han registrado avances significativos en los sistemas financieros de varios países y en la capacidad de movilización de recursos internos. El desarrollo industrial ha permitido consolidar avances importantes inclusive en las industrias básicas y el conocimiento tecnológico acumulado en los cuadros técnicos y en la fuerza de trabajo es ya apreciable. Al menos en los principales países de área, la formación de capital descansa mayoritariamente en la propia producción de bienes de capital y las infraestructuras técnico-científicas han madurado lo suficiente como para modificar sustancialmente el proceso tradicional de cambio tecnológico vía el "trasplante" de conocimientos descle los países avanzados. Eistos hechos, sumados al formidable potencial de recursos naturales de la región, constituyen una plataforma importante para la aceleración del desarrollo. Inclusive en la producción agropecuaria, donde ha resultado hasta ahora más evidente el subdesarrollo latinoamericano, se observan avances notables en los últimos años. Estas consideraciones no implican ignorar la magnitud del atraso económico y de los problemas sociales reflejados en el subempleo, la marginalidad, la.desnutrición, el analfabetismo que afecta a importantes contingentes de la población de los países latinoamericanos. Pretenden, simplemente, enfatizar el potencial de recursos disponibles y la aptitud para el desarrollo.

En la experiencia de la región, los avances políticos e institucionales también apuntan hacia una mayor aptitud para el desarrollo. Son varios los países latinoamericanos que han establecido estructuras políticas e institucionales aptas para Ia aceleración del desarrollo. La reciente consolidación institucional en la Argentina es una contribución importante en este proceso. Puede afirmarse que el problema del desarrollo latinoamericano no descansa primordialmente en la disponibilidad de recursos materiales y capacidad financiera, sino en la formulación de modelos políticos viables capaces de encuadrar la transformación económica y social en el largo plazo y asegurar la integración de las sociedades latinoamericanas. Integración tanto en lo que se refiere a los distintos grupos sociales como al plano regional, donde subsisten algunas de las manifestaciones más agudas del subdesarrollo latinoamericano.

En lo que se refiere al desarrollo del sistema industrial, la experiencia de los últimos años revela que varios países latinoamericanos han alcanzado ya madurez como para acrecentar rápidamente 
sus exportaciones de manufacturas y participar activamente en el comercio mundial de esto productos. Esto es cierto inclusive para manufacturas sofisticadas provenientes de las ramas químicas y mecánicas, en las cuales se registran corrientes de exportaciones significativas, no sólo en el plano intralatinoamericano, sino también, en las destinadas a las economías avanzadas. Esta expansión de las exportaciones de manufacturas constituyen un aporte decisivo para superar el estrangulamiento externo que ha frenado el desarrollo de la mayor parte de los países latinoamericanos y para ensanchar el horizonte del desarrollo manufacturero elevando los niveles de eficiencia, facilitando la especialización al nivel de productos y la obtención de economías en escala $y^{\prime}$ una más activa incorporación de la tecnología moderna.

En el ámbito de la integración latinoamericana se advierte también avances que fortalecen las posibilidades de desarrollo de la región y su posición negociadora frente al resto del mundo. Es cierto que el enfoque de integración a nivel continental, concebido en el Tratado de MIontevideo, quedó parcialmente frustrado por el incumplimiento de las metas propuestas en el Tratado. Pero no puede ignorarse su influencia en la promoción del comercio de manufacturas que constituyen ya una parte fundamental del intercambio. Sin embargo, todavía en 1972 las exportaciones intralatinoamericanas continuaban representando menos del $15 \%$ de las exportaciones totales de los países miembros.

Uno de los avances más importantes de la integración en los últimos años está constituido por el Acuerdo de Cartagena que instrumenta el ambicioso programa de formación de una Unión Aduanera entre los Países Andinos y la aplicación de políticas comunes de desarrollo al nivel de los acuerdos de integración para sectores específicos de las industrias dinámicas, las normas para la importación de tecnología y el tratamiento común del capital extranjero. Más allá de los avances concretos que se han logrado hasta la fecha, el proceso andino implica la formación de una experiencia común y de objetivos compartidos que presumiblemente acrecentarán el ritmo del proceso de integración y desarrollo con el correr de los años.

En otras áreas, particularmente en el Cono Sur, se advierte una más activa política de cooperación bilateral. Tal el caso de los acuerdos de Paraguay con Argentina, por un lado, y Brasil, por otro, para el aprovechamiento de los recursos hídricos de la región. Lo mismo ocurre con la cooperación argentino-uruguaya en la misma materia. Se han generalizado, además, acuerdos de cooperación en otros niveles como los celebrados por las empresas petroleras de Ecuador y Perú con las de otros países del área y esquemas para 
el aprovechamiento conjunto de recursos como gas natural y minerales. Los avances en el desarrollo de la infraestructura física son también significativos y un reciente inventario elaborado por el BID en la materia, revela la amplitud de las realizaciones posibles en este campo.

En resumen, los cambios del contexto internacional y la mayor madurez latinoamericana sientan bases sólidas para una profundización de las relaciones de los países del área con el mundo desarrollado, incluyendo la CEE. Conviene insistir. No debe esperarse que esa profundización provenga primordialmente de una mayor generosidad de los países europeos y del resto del mundo en desarrollo, tanto en materia de transferencias de recursos como de apertura de sus mercados a las exportaciones latinoamericanas. Dependerá, por el contrario, de la capacidad de los países latinoamericanos y europeos de encontrar, en el contexto de las relaciones económicas internacionales y de las tendencias vigentes, cauces concretos de cooperación de interés recíproco apoyado en criterios de rentabilidad más que en valoraciones éticas. También cabe señalar que este proceso no depende exclusivamente de las decisiones a nivel de los sectores públicos. El estrechamiento de los vínculos comerciales, financieros y tecnológicos, entre empresas privadas de ambos espacios económicos ofrecen también un amplio campo de posibilidades.

\author{
III. - LA GEE Y LA AMÉRICA LATINA EN EL NUEVO \\ ORDENAMIENTO ECONÓMICO INTERNACIONAL
}

\title{
1. Cambios en la posición internacional de la economia norteamericana
}

Desde el fin de la Segunda Guerra Mundial y prácticamente clurante toda la década de 1960, el déficit de la balanza cle pagos de los Estados Unidos jugó un papel funclamental en la expansión de la economía mundial, particularmente de Europa Occidental y Japón. En el período 1950-57 la balanza cle pagos de los EE.UU. arrojó un déficit anual medio de U\$S 1.300 millones. El superávit en las transacciones comerciales fue superado por las exportaciones de capitales y otros gastos de los Estaclos Unidos en el exterior. Esto estimuló el proceso de recuperación y desarrollo de las economías europeas y Japón generando un apreciable superávit en las transacciones externas de esos países y una expansión cle la liquidez y el ingreso. Entre esos años, las reservas oficiales de los países industrializados de Europa, 
excluyendo el Reino Unido, aumentaron de U\$S 5.100 millones a U\$S 12.600 millones.

Este proceso contribuyó de manera decisiva al restablecimiento de la convertibilidad de las monedas europeas en $1959 \mathrm{y}$ al progresivo desmantelamiento de barreras arancelarias, levantadas a partir de la gran depresión de 1930, que habría de materializarse en las negociaciones en el GATT de la Rueda Dillon y de la Rueda Kennedy.

EI déficit de la balanza de pagos estadounidense jugó también un papel fundamental en la generación de liquidez cuando la congelación del precio del oro a la paridad de U\$S 35 la onza desalentó su producción y orientó crecientes proporciones de la misma hacia usos no monetarios. En la década del 60 las reservas mundiales de oro monetario aumentaron de U\$S 38.000 millones a U\$S 39.000 millones, esto es, un crecimiento anual de $0,3 \%$, frente a un crecimiento muy rápido del comercio y las relaciones financieras internacionales. Ante la posición declinante de la libra, el sistema monetario internacional se apoyó crecientemente en un patrón clólar-oro.

Hasta 1957 estas tendencias no comprometieron las tenencias de resèrvas en oro de los Estados Ưnidos que, en ese año, se mantenían en el equivalente de U\$S 22.000 millones. A partir de fines de la década del 50 la situación tendió a cambiar rápidamente. Por un lado, aumentó el déficit de la balanza de pagos de los Estados Unidos que, entre 1958 y 1961, alcanzó un promedio anual de alrededor de U\$S 2.700 millones. El deterioro continuado de la balanza de pagos norteamericano obedeció a dos procesos concurrentes: la rápida disminución del superávit de las transacciones comerciales - hasta registrar un déficit de $1971-$ y el mantenimiento de exportaciones de capitales y otros gastos en el exterior, que excedieron ampliamente el superávit en cuenta corriente.

En el período 1960-64 el superávit de la balanza comercial de Ios Estados Unidos alcanzó a U\$S 5.400 anuales, para bajar posteriormente y alcanzar, en 1970, sólo U\$S 2.100 millones. En 1971 se registró un déficit de U\$S 2.900 millones. La inflación interna y una relación incremento de salarios/productividad, francamente desfavorable en relación con otros países industriales, particularmente Japón, fue deteriorando la posición competitiva externa de los Estados Unidos y originó un crecimiento de sus exportaciones a tasas inferiores que la de los otros grandes países industriales. Entre 1958 y 1970 las exportaciones de los Estados Unidos crecieron en un $89 \%$ en comparación con el $533 \%$ de Japón y $283 \%$ de toda la Comunidad Económica Europea. La expansión de las importaciones de los Estados Unildos contribuyó a agravar el deterioro de la balanza comercial del país.

Este deterioro no desalentó la exportación de capitales a largo 
plazo, sobre todo a través de las corporaciones americanas. Las inversiones directas netas pasaron de un promedio anual de U\$S 1.800 millones en el período 1960-64 a U\$S 3.300 millones en 1965-69. En 1971 ascendieron a U\$S 4.500 millones. Por otro lado, el incremento de otros gastos en el exterior tendieron a incrementarse como consecuencia de los compromisos políticos y militares de los Estados Unidos en el plano mundial. En 1970 los gastos netos de defensa en el exterior alcanzaron a U\$S 3.400 millones y otros gastos netos a U\$S 2.700 millones.

El déficit de la balanza de pagos estadounidense se reflejó en una notable disminución de sus tenencias de oro, que de U\$S 22.000 millones en 1957, se redujeron a U\$S 10.507 millones a mediados de 1971. Simultáneamente, aumentaron las tenencias de dólares en el resto del mundo. A mediados de 1971 esas tenencias alcanzaban a U\$S 64.200 millones, de los cuales U\$S 47.500 millones estaban en manos de las autoridades monetarias del resto del mundo.

El sistema monetario internacional estuvo sujeto a profundas y crecientes tensiones a partir de fines de la década de 1950. Los movimientos de capital de corto plazo acrecentaron el desequilibrio de las cuentas corrientes de los balances de pagos de los principales países creando sustanciales incrementos en la liquidez internacional y graves perturbaciones en los mercados cambiarios.

Vinculando la evolución de los acontecimientos monetarios con la expansión económica y el proceso de la interdependencia creciente entre los países desarrollados al nivel del comercio, las inversiones y las transferencias de tecnología, se advierte el papel fundamental jugado por el déficit de balance de pagos de los Estados Unidos en esos procesos. Al mismo tiempo, permitió a ese país, pese a la disminución paulatina de su superávit en la cuenta corriente de su balance de pagos, financiar sus compromisos internacionales derivados de su gravitación militar y política y a las corporaciones norteamericanas realizar una expansión de actividades sin precedentes en el resto del mundo.

Este "modelo" de funcionamiento de la economía internacional y de integración entre las economías avanzadas, fue progresivamente erosionado por el rápido desarrollo de la CEE y del Japón y la pérdida paulatina de la posición hegemónica con que los Estados Unidos surgieron de la Segunda Guerra Mundial. La crisis de confianza en la convertibilidad del dólar y la resistencia de los principales países industriales de ampliar sus tenencias de dólares como contrapartida de la expansión de las inversiones y los gastos de los Estados Unidos en el exterior, alteraron las bases de funcionamiento del sistema monetario internacional de postguerra y crearon la necesidad de restablecer el equilibrio en el balance de pagos norteame- 
ricano. Esto ha planteado la necesidad de la revisión del ordenamiento monetario internacional y asentar sobre nuevas bases el proceso de expansión e interdependencia entre las economías avanzadas.

La obtención de un superávit en sus transacciones exteriores ha sido un objetivo generalizado en los países comunitarios y Japón, como instrumento clave de la expansión de la demanda y de la liquidez interna y del financiamiento de las exportaciones de capital. Al asumir los Estados Unidos el mismo objetivo, la expansión de la liquidez internacional debe dejar de apoyarse en el incremento de las tenencias de dólares como activo de reserva. Por otra parte el proceso de expansión e interdependencia entre los países avanzados debe realizarse en condiciones de equilibrio del balance de pagos de los principales participantes del sistema.

\section{Nuevas bases del ordenamiento económico internacional}

No puede suponerse que este cambio en el papel de la economía norteamericana debilitará las tendencias dominantes en la economía internacional. La expansión del intercambio y de las corrientes de capital y tecnología entre los países avanzados continuará bajo el impulso del progreso tecnológico y su impacto en el incremento del ingreso real y la creciente complejidad de las estructuras productivas, que abren permanentemente nuevos cauces de complementación dentro del mundo desarrollado.

La experiencia reciente parece confirmar esta suposición ya que la rápida expansión de la producción y el comercio en los países avanzados, después de la mini-recesión de 1970 y 1971, ha sido concurrente con el reajuste de la paridad del dólar en diciembre de 1971 y principios de 1973, además de la revaluación del marco, el yen y otras monedas. El balance de comercio pasó de un déficit de casi 7 mil millones de dólares en 1972 a 1 mil millones, a nivel anual, en el segundo trimestre de 1972. Se espera que el balance de pagos de los Estados Unidos esté en equilibrio en 1974.

El abandono de la política nörteamericana de mantener la paridad del dólar a partir de la devaluación de diciembre de 1971, como así también la revaluación de varias monedas, han influido decisivamente en esa evolución del balance de pagos norteamericano. ${ }^{10}$

La reacción de los países europeos y Japón frente a las devaluaciones norteamericanas implica que el ajuste del balance de pagos norteamericano no podrá dar lugar a un superávit permanente, sin que haya una respuesta de los otros países desarrollados. De allí el

${ }^{10} \mathrm{E}$. proceso ha sido también favorecido por la expansión de exportaciones norteamericanas de productos agropecuarios. 
reclamo generalizado para una estabilización de las paridades cambiarias en el seno de las negociaciones dentro del Comité de los Veinte. La reacción europea frente a la política norteamericana fue resumida recientemente por un observador europeo11 en los siguientes términos: "Europa no desea financiar la inversión norteamericana acumulando dólares inconvertibles, ni facilitarla contribuyendo a un excedente comercial norteamericano mediante una limitación de sus propias exportaciones o gracias a una invasión de su propio mercado, es decir un riesgo para el empleo de los europeos". $\mathrm{Y}$ agrega: "Europa duda con razón que un país que saca ya 8 mil millones de dólares de ingresos de sus inversiones acumuladas deba tratar de recuperar un excedente comercial". Cuestiona, además, los incentivos impositivos otorgados en Ios Estados Unidos para las inversiones de las corporaciones norteamericanas en el exterior.

Estas son cuestiones centrales en las tratativas actualmente en curso entre los Estados Unidos, la GEE y Japón y se refleja plenamente en las negociaciones comerciales y monetarias en el seno del GATT y el FMI. En el campo monetario, el equilibrio del balance de pagos norteamericano plantea la necesidad de una nueva fuente de liquidez internacional que sustituya al dólar, visto el papel declinante del oro. De este modo, como se sostiene, en el Informe del Comité de los Veinte a la Junta de Gobernadores del FMI, los Derechos Especiales de giro se convertirán en el principal motivo de reserva y el papel del oro y de las monedas de reserva será reducido. Esta cuestión, junto al establecimiento de un nuevo proceso de ajuste de los desequilibrios del balance de pagos y de las normas para evitar la acumulación de déficit o superávit por parte de los países miembros del sistema, constituyen el problema central de la reforma monetaria. Los avances en este campo son significativos y revelan que los principales países han alcanzado ya un acuerdo básico sobre el establecimiento de normas que aseguren el equilibrio de largo plazo de sus balances de pagos. Como sostuvo el Director Gerente del FMI en sus observaciones de resumen sobre la reunión de Nairobi: "Debo enfatizar que existe una amplia base de acuerdo sobre los principios básicos de un nuevo sistema monetario. Estamos de acuerdo que el sistema debe basarse en paridades estables pero ajustables con clisposiciones permisivas de la fluctuación (floating) en circunstancias especiales; que deben establecerse arreglos para la convertibilidad; que los DEG deben ser el activo central de reserva del nuevo sistema; que el volumen de la liquidez global debe ser mantenido bajo un control internacional efectivo; que

${ }^{11}$ Pierre Uri, El contencioso Europa-América, Comunidad Europea, Bruselas, junio de 1973. 
derechos y obligaciones deben ser aplicados simétricamente a países deficitarios y superavitarios; y que el nuevo sistema debe tomar plena cuenta de las necesidades y aspiraciones de los países en desarrollo". 12

En la práctica, sobre este último punto es que existe menos acuerdo.

Puede suponerse que de las negociaciones comerciales y monetarias en curso surgirá un nuevo ordenamiento económico internacional que facilitará la continuada expansión e integración de las economías industriales avanzadas. Si se vinculan estos desarrollos con las negociaciones en la Conferencia sobre la Seguridad y la Cooperación en Europa, las realizadas entre la URSS y los Estados Unidos sobre el control de armas estratégicas y los entendimientos alcanzados entre este último país y China, se advierte una estabilización de las relaciones políticas y militares que facilitarán aún más el desarrollo de las fuerzas expansivas existentes en la economía internacional. Un hecho significativo de este proceso es la progresiva disminución del peso relativo de los gastos militares de las grandes potencias con respecto a los principales agregados económicos. Hace una década los gastos militares mundiales eran aproximadamente equivalentes al del valor de las exportaciones mundiales; actualmente representan alrededor del $50 \%$. También se registra una disminución de la relación entre esos gastos y el producto mundial. Esas erogaciones repiesentan aun el empleo de una cuantiosa masa de recursos pese a que han crecido menos que la producción y el comercio mundiales. Con todo, esta declinación puede interpretarse como una manifestación de la distensión política internacional.

\section{El problema inflacionario}

En el panorama actual de la economía internacional el principal problema está planteado por el aumento de las presiones inflacionarias. En el primer semestre de 1973 los precios han aumentado a la tasa anual del $6 \%$ en los países industriales. Esto es, cerca del doble del incremento en la década de 1960. En los meses recientes se ha acelerado el proceso inflacionario alcanzando en varios países avanzados tasas superiores al $10 \%$. Las distorsiones que el proceso inflacionario provoca en las corrientes de comercio y capitales y los graves problemas que genera al nivel de cada economía nacional, son causa de creciente preocupación en el orden internacional. Este problema fue la cuestión central, junto a la reforma monetaria, de la

22IMF Survey, octubre 8 de 1973. 
reciente reunión de Nairobi. Existe una amplia coincidencia sobre las consecuencias de la inflación pero divergencias apreciables sobre el diagnóstico del problema. Descle la perspectiva latinoamericana, esta es una vieja cuestión que ha nutrido el debate económico en la región durante buena parte de las décadas de 1950 y 1960. El tema reviste particular importancia para la marcha de la economía internacional y es de particular significación para la América Latina y el resto del mundo en desarrollo. En la medicla en que se atribuya la responsabilidad principal de la inflación al exceso de liquidez y cle demanda, los paises industriales pueden caer en la aplicación de políticas monetarias y fiscales restrictivas que frenen la expansión de la producción y el comercio internacional. Para los patses en desarrollo esto sería negativo desde dos puntos de vista. Por un lado, por el efecto deprimente que ejercería sobre la demanda de productos primarios y manufacturas exportadas por esos países. Segundo, porque eliminaría toda posibilidad de establecer un vínculo entre los Derechos Especiales de Giro y la ayuda al desarrollo, como instrumento efectivo de la transferencia de recursos desde los países avanzados.

Sin embargo, parece imperar un enfoque pragmático sobre la naturaleza del problema. La experiencia latinoamericana revela que no existe una sola causa, ni siquiera una fuente dominante, de las presiones inflacionarias. Lo mismo es cierto para la inflación desencadenada en los países avanzados. Múltiples fuerzas están operando sobre los niveles de precios y el centro de gravedad de las presiones inflacionarias se desplaza de unos factores a otros. Poca duda cabe, por ejemplo, que la inflación registrada durante la minirecesión de 1970-71, tuvo su origen en la presión de los salarios y otros costos. Existía una evidente insuficiencia de la demanda y recursos ociosos y no podían atribuirse a las presiones de aquella el aumento de los precios. El proceso fue acertadamente definido como "stagflation". La recuperación posterior y el rápido crecimiento de la producción en 1972 y 1973 generó, en cambio, presiones alcistas adicionales del lado de la demanda. Las políticas monetarias y fiscales expansivas de los principales países tuvieron, en consecuencia, una cierta influencia sobre la evolución de los precios. Pero aun en estas circunstancias, la existencia de ciertos cuellos de botella en la oferta de algunos productos estratégicos, más que un exceso generalizado de la demanda, parece haber infiuido en el recrudecimiento inflacionario. Este se reflejó dramáticamente en el fuerte aumento, sin precedentes descle la guerra de Corea, de los precios de materias primas, alimentos y combustibles, que presio- 
naron los costos al alza ${ }^{13}$. La utilización de la capacidad productiva existente y el empleo han crecido durante la presente fase de expansión, pero difícilmente pueda decirse, en cualquiera de las grandes economias industriales, que se han movilizado totalmente los recursos ociosos. Por otra parte, es cierto que la administración de las políticas fiscal y monetaria, como herramientas antinflacionarias ha sido entorpecida en algunos paises por la expansión de la liquidez generada en cuantiosos superavits del balance de pagos. Los recientes debates sobre el problema revelan un reconocimiento de la complejidad del problema y de la multiplicidad de las causas clel proceso inflacionario. De alli que cabe esperar un tratamiento pragmático de la cuestión que no comprometa, a través del empleo predominante de políticas monetarias y fiscales restrictivas, la continuada expansión de la producción y el comercio internacionales. Como sostuvo recientemente el Director Gerente del FMI: "In la medida en que las presiones inflacionarias surgen de características específicas de la estructura económica y social, no pueden ser enfrentadas exclusivamente por instrumentos que controlen la demanda; otras técnicas -incluyendo efectivas políticas de ingreso- deben ser aplicadas"14. Este es un lenguaje conocido para el enfoque "estructuralista" de la inflación latinoamericana.

Conviene agregar en el conjunto de medidas antinflacionarias, aquellas destinadas a promover la rápida expansión de la producción en aquellos productos cuyas restricciones de oferta han gravitado en el repunte de los precios. Esto incluye, naturalmente, el aumento de la producción en países en desarrollo y constituye un campo importante para la expansión de las exportaciones de esos países. En el caso del petróleo, la solución de los graves problemas de abastecimiento actuales que enfrenta Europa, Japón y, en menor medida, los Estados Unidos, tienen su respuesta en el plano político antes que en el económico.

Entre los factores que contribuirían a la contención de las presiones inflacionarias se cuenta la estabilización de los mercados cambiarios, el desaliento de los movimientos especulativos de capital y un crecimiento ordenado de la liquidez internacional.

El diagnóstico de la inflación y las medidas para enfrentarla en los paises industrializados son de particular importancia para los países en desarrollo. Como señalaron algunos representantes de estos países en la reunión del FMI en Nairobi, no debería atribuirse al vínculo entre la creación de los Derechos Especiales de Giro y la

${ }^{13} \mathrm{El}$ aumento de precios de los productos primarios fue estimulado por maniobras especulativas y las expectativas generaclas por la devaluación del dólar y la libra esterlina.

${ }^{14}$ Discurso ante el UN-ECOSOC, IMF Survey, octubre 22 de 1973. 
ayuda al desarrollo una incidencia inflacionaria adicional. Si es cierto que las presiones inflacionarias provienen en gran parte del lado de los costos y de las restricciones de oferta de ciertos productos, antes que de presiones excesivas del lado de la demanda y del pleno empleo de los factores productivos, entonces, aquel vínculo y la creación consecuente de liquidez daría lugar a una expansión de la producción en los países industrializados y no a presiones adicionales sobre los precios.

A partir de la década de 1930 los países industrializados lograron enfrentar con éxito el problema económico central: la insuficiencia de la demanda efectiva para mantener niveles aceptables de ocupación e ingresos. Más allá del nuevo equilibrio entre los países industrializados, que parece en buen camino de lograrse, la cuestión central actual es la de asegurar la expansión continuada de la producción y el comercio internacionales en condiciones razonables de estabilidad de precios. El pragmatismo con que se está abordando el tema y la interdependencia de los intereses fundamentales de los países industriales, permite suponer que se alcanzará un grado suficiente de concertación de las políticas económicas para contener la inflación sin comprometer la expansión de la producción y el comercio.

\section{Significación de la expansión de la producción y el comercio en los paises avanzados}

El cumplimiento de estas previsiones son de particular importancia para la América Latina y sus relaciones con la GEE y el resto del mundo desarrollado. Cabe esperar que la expansión continuada de las economías industrializadas y del comercio internacional amplíe los mercados para las exportaciones latinoamericanas y la disponibilidad de recursos financieros y tecnológicos. Se insiste, por lo tanto, en que el contexto externo del desarrollo latinoamericano es favorable para la profundización de los vínculos internacionales de la América Latina.

Desde una perspectiva histórica. conviene, sin embargo, marcar una diferencia con la experiencia latinoamericana desde mediados del siglo XIX hasta la gran depresión de 1930. Entonces, el desarrollo latinoamericano fue impulsado "desde afuera" por la expansión de la demanda internacional de productos primarios y la corriente de capitales que financió buena parte de la expansión de la producción exportable. En las condiciones contemporáneas, el desarrollo depende básicamente de la capacidad interna de transformación y de movilización de recursos internos. En otros términos, el liderazgo del 
desarrollo no puede delegarse en la demanda ni en el ahorro externo.

Desde este punto de vista, se advierte que el futuro de las relaciones entre la CEE y la América Latina dependerá de la interacción de un conjunto de tendencias que operan en la economía internacional y en el propio desarrollo interno de los países latinoamericanos y de su integración. La expansión europea amplía los mercados para las exportaciones latinoamericanas y generará mayor disponibilidad de recursos financieros y tecnológicos para ser orientados a la América Latina y, por cierto, al resto del mundo en desarrollo. Pero esta expansión de los vínculos CEE-América Latina deberá insertarse en un desarrollo latinoamericano que se orienta hacia la formación de estructuras industriales complejas, con una creciente capacidad de acumulación y de generación de tecnología, la diversificación de las exportaciones y la constitución de modelos de desarrollo independientes con control nacional de los sectores claves del aparato productivo. Estas tendencias en el desarrollo latinoamericano ensancharán las bases para la expansión del comercio con la CEE y la captación de recursos. En buena medida, la concreción de estas perspectivas dependerá de las decisiones de la CEE en relación a Ia Política Agricola Común y al régimen preferencial establecido con los países vinculados por los acuerdos de Yaundé, en la medida en que estas áreas de la política comunitaria restringe el acceso de exportaciones latinoamericanas e introduce preferencias discriminatorias en su contra.

\footnotetext{
IV. - LA PROYECGIÓN EXTERNA DE LA AMÉRICA LATINA Y SUS RELACIONES CON LA COMUNIDAD ECONÓMICA EUROPEA
}

\section{Transformación de las relaciones externas de la América Latina}

Predominan en la CEE algunas ideas claras sobre la América Latina. Una de ellas es que la región es una unidad histórico-cultural, pero que los intereses de los diversos países difieren a tal punto que no existe una posición con un grado suficiente de uniformidad como para proyectar una imagen externa coherente de la región. Esto debilita el entendimiento con América Latina, ya que en la GEE existe una clara tendencia a tratar los problemas de los países en desarrollo a nivel regional. Otra opinión generalizada destaca la poca utilidad de los foros multinacionales y de carácter global, como la UNCTAD, para encarar los problemas de las relaciones entre Europa $y$ el mundo en desarrollo. Corolario de esta opinión es la tendencia a 
tratar los problemas y negociar, no sobre la base de principios o declaraciones generales, sino sobre problemas concretos al nivel de productos específicos, términos del financiamiento, tratamiento de inversiones y otras cuestiones. Es curioso observar que, mientras en Europa se está realizando un debate a un alto nivel de generalización y atendiendo al largo plazo, en relación a los países en desarrollo se propicie un enfoque pragmático a corto plazo. Por las razones señaladas, y $\sin$ perjuicio de la necesidad ineludible de tratar las relaciones cle América Latina con la CEE en términos pragmáticos y de corto plazo, parece indispensable terciar activamente en el plano ideológico y político, donde se están gestando los esquemas que encuadrarán los cambios futuros de la proyección europea hacia la América Latina. En la reciente conferencia de Estocolmo, se destacó el carácter global cle las relaciones entre la región y los países desarrollados.

La falta de una acción orgánica latinoamericana frente a Europa, más allá de las posiciones fijaclas en CECLA, es sin duda un factor de debilitamiento de la posición negociadora de la región. Esa ausencia refleja la diversidacl de las situaciones nacionales en relación a los problemas del café, cacao, el azúcar, las carnes o los productos agrícolas de clima templado. También es diferente la aptitud de cada país latinoamericano para penetrar en los mercados de manufacturas en Europa.

De todos modos, los paises latinoamericanos enfrentan la necesidad impostergable de acordar posiciones frente a la CEE y los otros países desarrollaclos que fortalezcan sus intereses nacionales. De allí que el proceso de cambio político y social actualmente en curso en la región no debería desalentar la búsqueda persistente de nuevos entendimientos latinoamericanos para reactivar la integración regional-que sigue siendo una de las respuestas fundamentales a los problemas actuales- y fortalecer la proyección externa de la región.

Los países latinoamericanos enfrentan la necesidad de replantear sus relaciones recíprocas y su proyección externa sobre bases nuevas, más agresivas y ambiciosas que en el pasado reciente. Tanto los cambios en el encuaclre internacional, como en los procesos nacionales de los países de la región, convergen hacia la necesidad impostergable de ese replanteo.

La crisis del sistema de relaciones de la América Latina con los países clesarrollados, incluyendo la GEE ampliada, no podría solucionarse totalmente con la revitalización de las exportaciones de productos primarios y la expansión de manufacturas, mano de obra intensivos y de baja intensidad de capital y tecnología. Esto contribuiría, sin duda, a la expansión de las exportaciones, pero no alteraría la tendencia al deterioro de la posición internacional de la Améri- 
ca Latina. De todos modos, una estrategia de promoción de exportaciones incluye un mejoramiento del acceso de la producción latinoamericana a los mercados de Jos países avanzados y la reducción de las barreras proteccionistas como, por ejemplo, la política agrícola común de la CEE y la política norteamericana en el mismo sector. En relación a la $\mathrm{CEE}$, el enfrentamiento al carácter discriminatorio y de reciprocidad de los acuerdos establecidos entre la Comunidad y numerosos países en desarrollo constituye otro elemento fundamental para la defensa de numerosos productos exportados por países latinoamericanos.

En relación a los productos primarios, algunos conservan un dinamismo apreciable. Al caso del petróleo, cabe agregar los minerales no ferrosos, mineral de hierro, cereales forrajeros y carnes bovinas. Radican aquí buena parte de la capacidad exportadora de la América Latina.

Pero, en un sentido más amplio y trascendente, la superación de aquellas crisis requiere un cambio fundamental en la orientación del desarrollo industrial latinoamericano. Se trata, ahora, de proyectar: la producción industrial al exterior, incluyendo la de los sectores industriales dinámicos como las industrias mecánicas y químicas. De hecho, algunos países han logrado ya avances significativos en este campo, y las exportaciones de este tipo de manufacturas cuentan entre las de crecimiento más rápido. Sin embargo, representan todavía proporciones infimas de las exportaciones totales.

En ese proceso de transformación de la orientación del desarrollo industrial latinoamericano, la integración regional sigue ocupando un lugar insustituible. Poca duda cabe que la "autoridad" de la posición latinoamericana, frente a los países desarrollados, resulta notoriamente debilitada por la incapacidad de la región para avanzar con más empuje en un campo, como el de la integración, que depende de su propia decisión política.

América Latina, como espacio socio-económico, adquiere plena vigencia en su dimensión interna, esto es, como unidad de propósitos de desarrollo y transformación, en el marco de un proceso de interdependencia creciente entre los países de la región. La dimensión externa es también importante y se expresa en las posiciones comunes frente al resto del mundo en tomo de problemas específicos como el comercio de productos primarios y la incorporación de recursos financieros y la transferencia de tecnología desde el exterior. Pero parece lógico suponer que la proyección latinoamericana en el mundo del futuro dependerá, fundamentalmente, de la realización de su dimensión interna, es decir, de la integración regional.

No podría concebirse una respuesta de la América Latina frente a las tendencias de la economía internacional, incluyendo la amplia- 
ción de la CEE, que no incorporase la revitalización y profundización del proceso de integración regional.

Los otros dos grandes campos que integran una respuesta de la América Latina frente a aquellas tendencias se refieren a la ubicación de las filiales de corporaciones transnacionales y el desarrollo tecnológico. La ubicación de esas filiales dentro de la América Latina y en el mundo no comunista, en el desarrollo de la producción (particularmente en el campo industrial), el comercio internacional y las transferencias de tecnología, impiden formular una estrategia de relaciones internacionales sin considerar el papel que se les asigna a las mismas.

Por distintas vías, las tendencias predominantes en la América Latina son las de compatibilizar la participación de esas filiales y de su máximo aporte de recursos, tecnología y capacidad gerencial, con el control nacional de los principales centros de decisión en cada país.

En materia tecnológica, estrechamente relacionado al problema de las filiales de las empresas extranjeras, es necesario considerar la consolidación de las infraestructuras científicas y tecnológicas nacionales, la integración de las mismas a nivel regional y la transformación de las condiciones de la transferencia de tecnología desde el exterior, como requisitos fundamentales para establecer vínculos con los países desarrollados sobre nuevas bases. La formulación del programa de desarrollo tecnológico en el Grupo Andino, los avances registrados en los países latinoamericanos en la formulación de políticas tecnológicas y los encuentros internacionales como el de CACTAL, revelan la prioridad que este campo ha adquirido en la estrategia del desarrollo latinoamericano.

\section{Algunas áreas especificas de cooperación}

La cooperación entre ambos espacios económicos puede promoverse a través de la puesta en marcha de mecanismos específicos que estimulen intercambio, transferencia de recursos y cooperación técnica.

La incorporación de los países europeos a la estructura del BID constituye un paso de singular importancia para que los recursos europeos utilicen la experiencia del Banco en la evaluación de proyectos y su conocimiento de los problemas del desarrollo de los países latinoamericanos.

Los contactos entre la Comisión de la CEE y la Junta de Acuerdo de Cartagena es otra área importante de cooperación. En particular, puede ser útil para canalizar recursos y tecnología para la ejecución de proyectos en el ámbito de los acuerdos sectoriales de complementación industrial, como el existente en el sector metalmecánico y los 
que se están elaborando para la rama petroquímica y otros sectores. En el programa de desarrollo tecnológico del Grupo Andino, la experiencia de la GEE es también de particular significación.

El acuerdo no preferencial firmado con la Argentina y los negociados con Uruguay y Brasil, tienen cierta utilidad para despejar incertidumbres en las exportaciones de interés para esos países destinados al mercado comunitario.

Recientemente los países latinoamericanos prepararon un documento con proposiciones concretas, para ser considerado en las reuniones periódicas a nivel de Imbajadores que se realizan entre la CEE y los representantes permanentes latinoamericanos frente a la Comunidad. El documento sostiene la tesis de que las eventuales desgravaciones arancelarias y las preferencias deben ir acompañadas de medidas concretas para promover el intercambio y eliminar los obstáculos que frenan la expansión del comercio. Con este objetivo se propone la creación de un "Centro CEE/América Latina de expansión comercial", con sede en Bruselas. El Centro tendría el propósito de ampliar las informaciones disponibles sobre las oportunidades de exportaciones latinoamericanas a la CEE, mejorar los contactos a nivel oficial, facilitar las relaciones entre empresas exportadoras e importadoras, etc. El proyectado Centro cumpliría una amplia gama de tareas informativas y de promoción cle contactos que mejoraría el conocimiento recíproco, facilitaría la concreción de oportunidades de intercambio actualmente desaprovechadas. La otra propuesta concreta del documento mencionado se refiere a la mejora del Sistema de Preferencias Generalizadas. En este campo el documento propone incluir a los productos agxícolas, incluyendo los elaborados, en el sistema de preferencias sin restricciones especiales; suprimir los contingentes y restricciones aplicados actualmente a algunos productos industrializados; limitar en lo posible las medidas cle salvaguardia; ampliar el trato preferente a las barreras no arancelarias; reconocer el principio de "origen acumulado"; flexibilizar las normas administrativas de aplicación del sistema; y utilizar los datos estadísticos más recientes en la determinación del aumento anual de este volumen.

Existe un amplio campo para iniciativas concretas tendientes a promover el intercambio y la transferencia de recursos desde la GEE y estas propuestas latinoamericanas sirven el propósito de instrumentar prácticamente esas posibiliclades. Un enfoque imaginativo, en estas cuestiones permitiría aprovechar las múltiples posibilidades de profundización cle los vínculos CEE/América Latina que la evolución de la Comunidad de la economía mundial y el propio desarrollo de los países latinoamericanos están abriendo permanentemente, conforme se trata de analizar en este informe. 